TRABAJOS DE PREHISTORIA

68, N. ${ }^{\circ}$ 2, julio-diciembre 2011, pp. 219-236, ISSN: 0082-5638

doi: $10.3989 /$ tp.2011.11067

\title{
Hacia una Arqueología de la Etnicidad
}

\author{
Towards an Archaeology of Ethnicity
}

\author{
Manuel A. Fernández Götz $(*)$ \\ Gonzalo Ruiz Zapatero $\left.{ }^{*}\right)$
}

\section{RESUMEN}

Desde hace unas dos décadas, la búsqueda de la etnicidad a través de la cultura material viene disfrutando de un renovado auge en Arqueología. Este proceso, unido al replanteamiento del concepto en las Ciencias Sociales, ha llevado a reconsiderar tanto la propia concepción del fenómeno como las posibilidades de explorarlo en grupos del pasado. El presente artículo pretende contribuir a esta tarea de "repensar" la etnicidad a través de tres pasos. Tras una aproximación historiográfica a la temática, una serie de conclusiones teórico-metodológicas permiten avanzar en la construcción de una "arqueología de la etnicidad". Finalmente, se reflexiona sobre la Protohistoria, etapa en la que estas aproximaciones han generado mayor interés.

\begin{abstract}
In the last two decades the search for ethnicity through material culture has enjoyed a renewed boom in Archaeology. This process, which goes hand in hand with a reformulation of the concept in the Social Sciences, has led to a reconsideration of how the phenomenon itself is conceived as well as the possibilities of exploring it in groups from the past. This article attempts to make a contribution to the task of "rethinking" ethnicity in three steps: first a historiographic approach to the subject; second, a series of theoretical-methodological conclusions that will help in the ongoing task of constructing an "archaeology of ethnicity"; and, finally, a reflection on the period where these approaches have generated most interest: Protohistory.
\end{abstract}

Palabras clave: Arqueología teórica; Historia cultural; Posmodernismo; Edad del Hierro.

(*) Dpto. de Prehistoria, Facultad de Geografía e Historia, Universidad Complutense de Madrid. C/ Prof. Aranguren s/n. 28040 Madrid. Correos e.: manuelferg@yahoo.es; gonzalor@ghis.ucm.es

Recibido: 20-XI-2010; aceptado: 4-II-2011.
Key words: Theoretical Archaeology; Culture History; Postmodernism; Iron Age.

\section{INTRODUCCIÓN}

De todas las formas de identidad social existentes (Díaz Andreu et al. 2005) la etnicidad es, seguramente, la que mayor controversia genera desde los ensayos de Kossinna y su utilización por la Alemania nazi (Arnold 1990, 1992; Legendre et al. 2007; Fernández Götz 2009a). Lo "étnico" se ha asociado en numerosas ocasiones al totalitarismo, a los esencialismos de sangre y, en definitiva, a una visión del pasado teñida de fuerte racismo. Sin embargo, desde hace algunas décadas la Arqueología viene prestando una renovada atención a la problemática (Hodder 1982; Shennan 1989; Jones 1997; Fernández Götz 2008). Ello en el fondo constituye sólo un pequeño reflejo de un interés mucho más global en la Antropología (Eriksen 1993; Banks 1996; Ramírez Goicoechea 2007), la Sociología (Jenkins 1997; Fenton 2003; Song 2003; Brubaker 2004; Smith 2008) o la Psicología (Verkuyten 2004). Estas renovadas aproximaciones son el punto de partida para abordar los objetivos del artículo. El primero es ofrecer una breve historiografía de las aproximaciones arqueológicas a la etnicidad desde los ensayos iniciales del Historicismo Cultural hasta las últimas aportaciones posprocesuales. El segundo, plantear propuestas teóricometodológicas derivadas de la redefinición del propio concepto. Por último, se apuntan algunas vías para el estudio de esta temática en la Protohistoria, seguramente el período donde ha despertado el mayor interés dentro de la arqueología española. 


\section{DEL ESENCIALISMO AL POSMODERNISMO: BREVE HISTORIOGRAFÍA DE LAS INTERPRETACIONES ÉTNICAS EN ARQUEOLOGÍA}

Cuando se habla de 'etnicidad', uno de los principales problemas es que muchas veces se coincide en el uso del término, pero no en su conceptualización. Los planteamientos esencialistas del denominado paradigma étnico-cultural partían de una equiparación simple y simplista entre 'pueblo', 'lengua' y 'cultura arqueológica'. En cambio, las últimas propuestas derivadas de postulados posprocesuales destacan el carácter subjetivo, fluido y situacional de la identidad étnica (Fig. 1). Diseccionar y clarificar las distintas significaciones a través del análisis historiográfico se antoja una tarea básica en la construcción de planteamientos teórico-metodológicos.

Las interpretaciones étnicas, entendidas tradicionalmente como la adscripción de restos materiales a 'tribus' o 'pueblos', han disfrutado de una larga y continuada trayectoria en la investigación arqueológica (Jones 1997; Brather 2004; Fernández Götz 2008). Estas identificaciones están ya presentes en los testimonios de autores como Tucídides o Tácito, pero fue a partir del Renacimiento, y muy especialmente del Romanticismo, cuando aumentó de forma significativa el interés por atribuir elementos de la cultura material a pueblos históricamente conocidos (Sklenár 1983). El desarrollo de la disciplina arqueológica daría su impulso definitivo a las interpretaciones étnicas (Meinander 1981). Hacia finales del siglo XIX e inicios del XX las variaciones geográficas eran interpretadas cada vez más como expresiones de diferentes 'pueblos' prehistóricos. Esta evolución se debió fundamentalmente a dos motivos. El gran incremento de datos disponibles puso de manifiesto significativas variaciones geográficas en el registro arqueológico que no podían ser explicadas únicamente a partir de la evolución unilineal. A su vez, el auge generalizado del nacionalismo trataría de instrumentalizar la arqueología para delimitar las 'áreas culturales' y manifestar la 'grandeza cultural' de los respectivos pueblos que eran considerados la base de los distintos Estados-nación (Brather 2004: 19-26; Fernández Götz 2008: 22-25).

En este contexto cabe encuadrar la obra del arqueólogo alemán G. Kossinna, indisociablemente ligada a la historia de las interpretaciones étnicas (Veit 1989; Fernández Götz 2009a). Desde un enfoque histórico y particularista, equiparaba de modo simplista 'pueblo', 'lengua' y 'cultura arqueológica’ (Kossinna 1911). Su paradigma étnico estaba basado en una visión esencialista de los grupos étnicos, concebidos como unidades estáticas y homogéneas. Estos principios se sintetizan en su famoso axioma: "En todas las épocas, las provincias culturales arqueológicas que
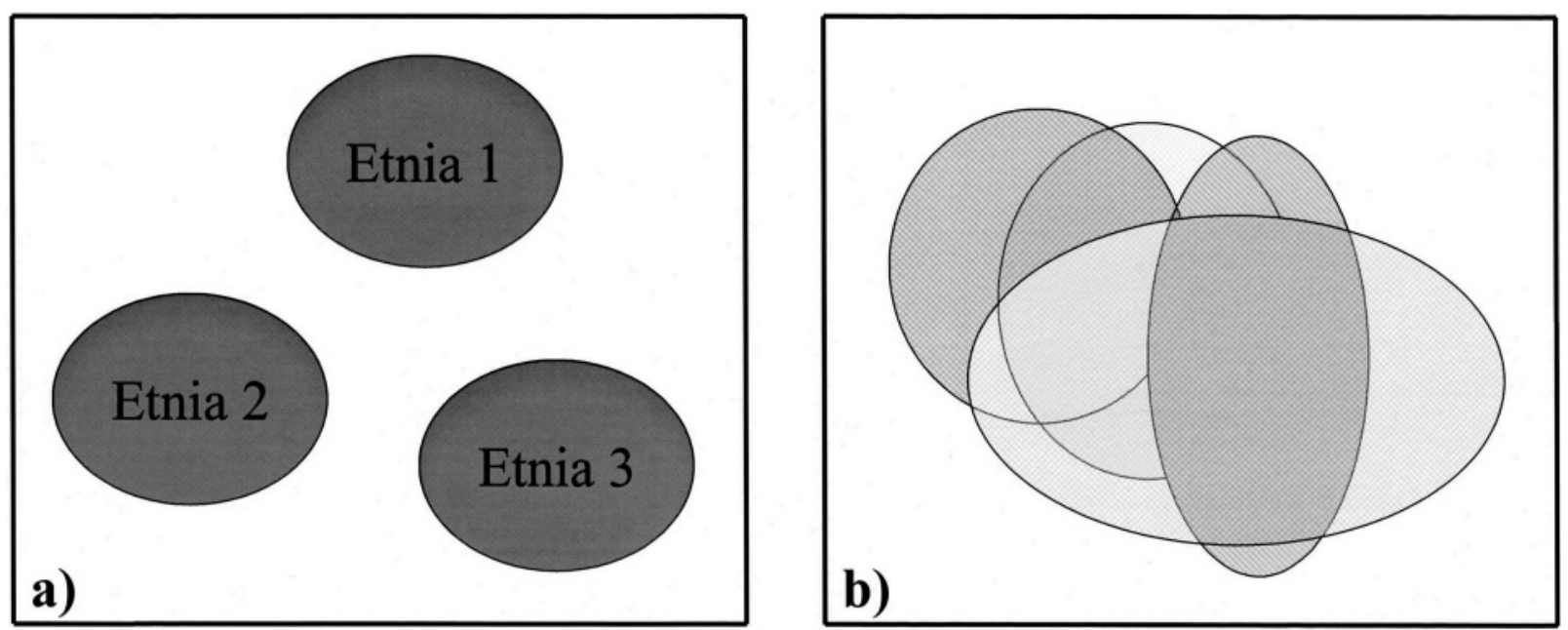

Fig. 1. a) Visión esencialista: grupos étnicos como entes homogéneos y aislados; b) La etnicidad reconsiderada: identidades que se solapan en el marco de una continua interacción (según Fernández Götz 2009b).

Trab. Prehist., 68, N. ${ }^{\circ}$, julio-diciembre 2011, pp. 219-236, ISSN: 0082-5638 doi: $10.3989 /$ tp.2011.11067 
aparecen claramente delimitadas corresponden a pueblos o tribus muy concretos"(1) (Kossinna 1911: 3). Los trabajos de Kossinna representan sólo 'la punta del iceberg' de un fenómeno mucho más global (Meinander 1981). A nivel nacional e internacional influyeron incluso en arqueólogos muy distantes de sus planteamientos políticos e ideológicos, como Childe (1929) o Bosch Gimpera (1932). Precisamente, la definición de cultura arqueológica de Childe (1929: V-VI) como un "conjunto constantemente recurrente de artefactos en el tiempo y en el espacio" contribuyó de forma decisiva a difundir una imagen de la Prehistoria como 'mosaico' de pueblos y culturas.

La instrumentalización nacionalista y racista de la Arqueología por regímenes totalitarios entre los que destaca la Alemania nacionalsocialista (Arnold 1990, 1992, 2006; Legendre et al. 2007), explica en buena medida el descrédito de las interpretaciones étnicas tras el final de la Segunda Guerra Mundial (Smolla 1979-80). Sin embargo, el creciente escepticismo respecto a las interpretaciones étnicas no conllevó, en la práctica, su total abandono. En muchos casos se sustituyó el término 'grupo étnico' por el más neutral de 'cultura arqueológica', sin una verdadera renovación de los principios subyacentes. La New Archaeology, por su parte, destacó por su crítica a las visiones normativistas de la cultura (Binford 1962, 1965) y, por ende, a la ecuación tradicional entre culturas arqueológicas y grupos étnicos. Las nuevas perspectivas reconocieron la multiplicidad de factores implicados en la variabilidad espacial del registro y desarrollaron nuevos marcos de análisis como la noción 'politética' de Clarke (1968). No obstante, la arqueología procesual apenas profundizaría en la problemática étnica por considerarla obsoleta y propia de la denostada arqueología histórico-cultural.

Frente al escepticismo imperante en Arqueología, entre las décadas de 1950 y 1970 una serie de avances fundamentales en Antropología y Sociología llevarían a redefinir el propio concepto de etnicidad. Teniendo como telón de fondo el rápido proceso de descolonización, los trabajos de Moerman (1965), Barth (1969) o Glazer y Moynihan (1975) promovieron una visión de los grupos étnicos como fenómenos dinámicos y situacionales. Esta evolución estuvo marcada por

(1) Traducción de las citas literales procedentes del alemán y el inglés a cargo de los autores. un debate entre perspectivas "primordialistas" e "instrumentalistas", diferenciadas por considerar la identidad étnica como una realidad a priori o a posteriori. Así, mientras las aproximaciones primordialistas defienden que el sentimiento de pertenencia a un grupo es innato, según las instrumentalistas la adopción de una identidad étnica puede venir dada por decisiones de tipo económico o político (Fernández Götz 2008: 65-76). Uno de los aspectos más importantes de esta etapa fue la consolidación de una visión emic de la etnicidad, con la edición del libro Ethnic Groups and Boundaries (Barth 1969) como principal hito. Según Barth, los grupos étnicos constituirían categorías de adscripción e identificación utilizadas por los actores mismos. Además, y en contra de las conceptualizaciones tradicionales, las distinciones étnicas no resultarían del aislamiento, sino de la interacción entre grupos.

La redefinición del concepto de etnicidad en las Ciencias Sociales, en un primer momento, apenas repercutió en las agendas de investigación arqueológica. No sería hasta finales de la década de 1970 cuando, de la mano de investigaciones vinculadas al denominado "debate sobre el estilo", se intenta reconciliar la brecha entre aproximaciones antropológicas y arqueológicas. Los trabajos etnoarqueológicos de Hodder (1982), Wiessner (1983) o Larick (1986) destacaron el papel activo del estilo en la expresión de la identidad y en la negociación de las relaciones sociales, reconociendo, además, que la expresión de la etnicidad podía estar restringida a un limitado elenco de atributos asociados con un referente étnico. Especialmente relevante resultó el estudio de Hodder (1982) sobre los límites étnicos en el distrito de Baringo (Kenia), donde analizó el comportamiento de la etnicidad en un contexto de interacción fronteriza. Según sus resultados el uso de la cultura material en la diferenciación entre grupos étnicos autoconscientes podía dar lugar a discontinuidades en la distribución de ciertos elementos del registro, abriendo la posibilidad de una identificación arqueológica. Sin embargo, también apuntaron que algunos grupos podían elegir estrategias de asimilación y otros mantener una identidad étnica sin reflejo en la cultura material, dando como resultado unos límites étnicos imperceptibles para los arqueólogos.

Los mencionados trabajos etnoarqueológicos ocurren durante los años 1980, cuando los estudios sobre etnicidad experimentan un discreto 
auge en Arqueología (Shennan 1989; Renfrew 1990; Olsen y Kobylinski 1991). Entre ellos cabe destacar el volumen Archaeological Approaches to Cultural Identity (Shennan 1989). En su introducción al mismo, Shennan (1989) planteará tres de los problemas que centrarán la atención de los investigadores durante la siguiente década: la conceptualización de la 'etnicidad'; la relación entre identidad étnica y cultura material, con una dura crítica a la ecuación entre culturas arqueológicas y grupos étnicos; y el alcance temporal del propio fenómeno, que el autor relaciona estrechamente con la emergencia de los 'Estados prístinos'.

El renovado interés por las cuestiones étnicas cristalizaría en el ethnic revival de la década de 1990, principalmente de la mano de dos factores. Desde una perspectiva estrictamente arqueológica se desarrollan las corrientes posprocesuales con su énfasis en los procesos de negociación social. A un nivel más amplio, la atención que acaparan los procesos identitarios en un mundo cada más globalizado (Hernando Gonzalo 2002; Jenkins 2004), donde los conflictos étnicos y los debates en torno a fenómenos como la inmigración se encuentran a la orden del día (Eriksen 1993; Ramírez Goicoechea 2007). A ello no es ajeno el fuerte auge de los estudios que analizan la interacción entre Arqueología y construcción de identidades contemporáneas, señalando los múltiples riesgos y distorsiones producidas tanto en el pasado como en el presente (Graves-Brown et al. 1996; Díaz-Andreu y Smith 2001; Rieckhoff y Sommer 2007). Algunos autores llegan a rechazar las aproximaciones arqueológicas a la etnicidad por su posible instrumentalización con fines actuales. A dicho argumento cabe contraponer que los análisis llevados a cabo por profesionales son preferibles a dejar este campo en manos de todo tipo de grupos de interés. Pese a que las categorías étnicas han sido frecuentemente manipuladas con fines políticos, tenemos que ser conscientes de que si los arqueólogos no abordamos esta problemática mediante análisis rigurosos otros continuarán utilizándola con motivaciones ideológicas.

Los últimos años han estado marcados por un debate teórico entre el enfoque instrumental y las teorías posmodernas. Las aproximaciones más innovadoras resultan deudoras de postulados procedentes de la sociología francesa, fundamentalmente de Bourdieu $(1972,1980)$, sin minusvalo- rar la influencia ejercida por Giddens (1984) o incluso un redescubierto Weber (1922). El punto de partida fue el trabajo de Bentley "Ethnicity and Practice" (1987), que introdujo en la antropología anglosajona ideas del postestructuralismo francés, sobre todo la Teoría de la Práctica de Bourdieu (1972) y su concepto de habitus. Definible como el conjunto de esquemas generativos a partir de los cuales los sujetos perciben el mundo y actúan en él, el habitus viene desempeñando desde entonces un importante papel en las aproximaciones a la identidad étnica. En Arqueología, el libro The Archaeology of Ethnicity (Jones 1997) representa el punto de inflexión para la entrada de estos planteamientos. En él se trata de superar la dicotomía entre objetivismo y subjetivismo, y entre primordialismo e instrumentalismo, a través de la aplicación del concepto de Bourdieu. En Historia Antigua la obra Ethnic identity in Greek antiquity (Hall 1997) ha marcado un antes y un después en las aproximaciones a la etnicidad. Desde entonces se han multiplicado los trabajos, pudiendo destacarse los del propio Hall (2002), Siapkas (2003) o Derks y Roymans (2009) en el campo de la Historia Antigua y la Arqueología del Mundo Clásico, Smith (2003) en el de la Egiptología, James (1999), Wells (2001) y Roymans (2004) en el de la Protohistoria e inicios de la 'romanización' o Reycraft (2005) en el de la Arqueología Andina. Todo ello sin olvidar que el estudio de los procesos de etnogénesis tiene grandes posibilidades en contextos de época medieval (Siegmund 2000) o moderna y contemporánea (Voss 2008).

En España, los estudios sobre etnicidad vienen experimentando un 'renacer' desde hace algo más de dos décadas, especialmente en la investigación protohistórica. El congreso Paleoetnología de la Península Ibérica (Almagro-Gorbea y Ruiz Zapatero 1992) supuso una referencia fundamental que ha dejado paso a estudios de orientación teórico-metodológica muy dispar. Hay libros de carácter general (Cruz Andreotti y Mora Serrano 2004; Fernández Götz 2008; Sastre Prats 2009), aproximaciones regionales sobre áreas como el Levante (Grau Mira 2005; Vives-Ferrándiz Sánchez 2007) o el Sur peninsular (García Fernández 2007; Wulff y Álvarez Martí-Aguilar 2009), así como monografías sobre grupos mencionados por las fuentes clásicas, como Celtíberos (Lorrio 2005; Burillo 2007), Iberos (Ruiz y Molinos 1993; Díaz-Andreu 1998), Vettones (Álvarez- 
Sanchís 1999; Ruiz Zapatero y Álvarez-Sanchís 2002) o Galaicos (González Ruibal 2006-07). Finalmente, destacamos el análisis crítico y en muchos casos deconstructivo de conceptos como 'Celtas' (Ruiz Zapatero 2001, 2005; Díaz Santana 2003), las contribuciones llevadas a cabo en otros ámbitos como el mundo griego (Cardete del Olmo 2006, 2009) o la renovación de las visiones en relación con la 'romanización' (Jiménez Díez 2008). Esta breve enumeración, ciertamente incompleta, sirve al menos para poner de manifiesto el interés que sigue generando la problemática hasta la actualidad.

\section{RECONSIDERANDO LA ETNICIDAD EN ARQUEOLOGÍA: PROPUESTAS TEÓRICO-METODOLÓGICAS}

Como consecuencia de la redefinición del concepto, hoy en día existe un amplio consenso en que, aunque puede estar basada en parte en elementos heredados, la etnicidad es en última instancia un tema de autorreconocimiento de grupo y de autoidentidad. Según autores como Hall (1998: 266-267), Cardete del Olmo (2009: 32) o Mac Sweeney (2009: 102) los dos criterios fundamentales de configuración de la etnicidad serían la reclamación explícita de una relación de parentesco y la conciencia de compartir una misma historia, lo que está asociado a un territorio concreto actual, anterior o imaginado. La identidad de los grupos étnicos se basa, por tanto, en buena medida sobre la noción de un pasado común (Hall 1998: 266-267). Ello se relaciona directamente con el papel crucial de los mitos de fundación, existentes en prácticamente todas las comunidades de la Antigüedad y muchas veces ligados a relaciones de poder en su seno (Gehrke 2000; Roymans 2004: 235-236; Smith 2008: $34-$ 35 y 40-46; Derks y Roymans 2009: 7-8). La 'tradición' -o, mejor dicho, la 'creación' o 'invención' de la tradición (Hobsbawm y Ranger 1983) - se constituye de esta forma en un elemento fundamental de todo proceso de etnogénesis y de reelaboración de identidades colectivas. A través de sus mitos de origen los grupos étnicos tratan de dar una apariencia 'natural' a procesos que son eminentemente culturales, construyendo narrativas legendarias que incluyen aspectos como una supuesta patria común, una batalla mitológica o una migración, por citar sólo algunos ejemplos (Smith 2008: 31). La elaboración de genealogías ficticias puede ser usada para justificar relaciones jerárquicas entre etnias y entre subgrupos de éstas. Pero los orígenes míticos, lejos de ser estáticos, se encuentran sometidos a continuas redefiniciones y manipulaciones que permiten adaptarlos a las circunstancias de cada momento histórico (Derks y Roymans 2009: 7-8). $\mathrm{Su}$ poder y vitalidad no deriva simplemente de las referencias al pasado, sino de la relevancia que poseen para el presente y el futuro del grupo (Gehrke 2000).

Estas renovadas perspectivas plantean notables dificultades para cualquier aproximación arqueológica ya que, como indica Herbert (2003: $105)$, en última instancia se intenta inferir a partir de los restos materiales cómo las gentes del pasado "se pensaron como distintas" de otras. Asimismo, toda asignación de etnicidad es en el fondo una simplificación: como cualquier categoría politética, sus límites son difusos (Ramírez Goicoechea 2007: 313). No obstante, el reconocimiento de que las relaciones entre etnicidad y cultura material son mucho más complejas y problemáticas de lo que asumían los enfoques esencialistas del 'paradigma étnico-cultural' no debe llevar a posicionamientos totalmente escépticos. Desde nuestro punto de vista, existe futuro para una arqueología de la etnicidad, entendiendo ésta como una arqueología crítica 'en construcción' enmarcada en el estudio más amplio de la identidad en el pasado (Hernando Gonzalo 2002; Díaz-Andreu et al. 2005; Insoll 2007). Es cierto que la tarea no resulta fácil y que las voces críticas deben ser bien atendidas (Brather 2004). La posibilidad de que no existieran solapamientos entre cultura material, etnónimo y lengua es real, y refleja la complejidad de relaciones entre las distintas esferas de la sociedad. Pese a ello, la cultura material como elemento activo en la práctica social puede encontrarse también implicada en el reconocimiento y en la expresión de la etnicidad (Jones 1997: 117-118). Los grupos étnicos pueden comunicar su identidad a través de elementos culturales consciente o inconscientemente seleccionados de un amplio repertorio cultural, lo cual deja abierta la puerta para una posible exploración arqueológica. Un concepto clave para esta discusión, que está adquiriendo una creciente importancia en las Ciencias Sociales, es el de 'materialidad': las personas crean cultura material y la cultura material las crea a 
ellas simultáneamente (Miller 2005; González Ruibal 2007). No se trata sólo de que la etnicidad pueda encontrar un reflejo material, sino que la propia cultura material crea identidad a través de producción cerámica, utilización de elementos de adorno, visibilización de fronteras, construcción de santuarios, etc. (Cardete del Olmo 2006: 193). Como parte esencial de las prácticas sociales dentro de los grupos, la cultura material participa activamente en la producción de representaciones discursivas de la identidad. Los límites étnicos y culturales pueden no coincidir, pero la afinidad de prácticas y experiencias proporcionan el núcleo sobre el que se construyen nuevos discursos de identidad en circunstancias históricas cambiantes (Jones 1998: 273). Las construcciones identitarias y étnicas son procesos sociales, y como tales pueden dejar sus 'huellas' en el registro arqueológico (Cardete del Olmo 2009: 34); que seamos capaces de reconocerlas e interpretarlas correctamente es ya otra cuestión.

Definir con mayor precisión qué entendemos por 'etnicidad' y 'grupo étnico' resulta ciertamente complicado. La mayor parte de las definiciones al uso, o son demasiado restrictivas como para dar cuenta de la complejidad del fenómeno o su amplitud hace imposible distinguir la identidad étnica de otros tipos de identidad social. Ante todo, hay que reconocer el carácter polifacético y por tanto enormemente difuso de la etnicidad. Por ello, tan necesario como establecer definiciones lo suficientemente rigurosas para asegurar el valor comparativo de los estudios en los distintos ámbitos (Ruby 2006: 59; Ruiz Zapatero 2009: 16-18), será profundizar en la variedad de niveles histórica y situacionalmente contingentes a los que puede hacer referencia la etnicidad.

Dicho esto, creemos útil presentar algunas de las definiciones más relevantes de las últimas décadas. Según Shennan (1989: 14) la etnicidad sería: "la identificación autoconsciente con un grupo determinado, basada, al menos en parte, en un área específica u origen común". Pese a su brevedad, establece tres rasgos básicos de cualquier definición de etnicidad: la propia percepción del grupo que en definitiva es lo que genera el sentido de identidad, la delimitación del territorio del grupo étnico y, finalmente, la asunción cierta o inventada de una continuidad a partir de unos ancestros comunes. Por su parte, Roymans (2004: 2) destaca la importancia de las dinámicas emicletic al definir la identidad étnica como: "el resultado temporal de un proceso de desarrollo colectivo de auto-imágenes, actitudes y conducta que tiene lugar en el contexto de interacción entre aquellos directamente implicados y los que están fuera". La conceptualización más completa se debe a Jones (1997: xiii), quien la define como "aquel aspecto de la auto-conceptualización personal que resulta de la identificación con un grupo más amplio por oposición a otros sobre la base de una diferenciación cultural percibida y/o una descendencia común". Un grupo étnico sería a su vez: "cualquier grupo de gente que se considera a sí mismo apartado de otros y/o es apartado por otros con los que interactúa o coexiste sobre la base de sus percepciones de diferenciación cultural y/o descendencia común”. Finalmente, esta autora define la etnicidad como: "todos aquellos fenómenos sociales y psicológicos asociados con una identidad de grupo culturalmente construida. El concepto de etnicidad se centra en las maneras por las que los procesos sociales y culturales se cruzan unos con otros en la identificación de grupos étnicos y la interacción entre ellos".

El sociólogo A. D. Smith (2008: 30-31) distingue dos usos del concepto de etnicidad, uno restringido basado fundamentalmente en los criterios de noción de descendencia común e historia compartida, y otro más amplio para el que propone una clasificación tripartita: 1) ethnic categories, 2) ethnic associations o ethnic networks y 3 ) ethnic communities o ethnies. Las primeras serían 'constructos', a menudo realizados desde el exterior, que agruparían a poblaciones que comparten algún elemento cultural similar y tal vez una determinada área geográfica, pero que pueden carecer de nombre con el que designarse a sí mismas, de un mito de descendencia y de un sentido de solidaridad común. Los ethnic networks presentan un cierto grado de actividades compartidas y de relaciones pero raramente unidad política, tendiendo a contar con un nombre colectivo, un mito de origen común y cierto grado de solidaridad, al menos entre las élites. Las ethnic communities serían poblaciones con un nombre propio y autodefinidas con mitos de origen y memorias históricas compartidas, elementos de cultura comunes y cierta solidaridad étnica. Según Smith (2008: 33), mientras la caracterización de una colectividad por otras puede delinear una ethnic category, las ethnic communities requieren de clara autodefinición. Este tercer nivel equivaldría, por tanto, a la noción de etnicidad de

Trab. Prehist., 68, N. ${ }^{\circ}$ 2, julio-diciembre 2011, pp. 219-236, ISSN: 0082-5638

doi: $10.3989 /$ tp. 2011.11067 
autores como Hall (1997, 1998) o Shennan (1989). Dejando de lado algunos detalles discutibles, la distinción de Smith resulta de notable interés, al proporcionar herramientas conceptuales muy valiosas para comprender casuísticas que no terminan de encajar desde una perspectiva más restringida, como veremos al tratar el caso de la Protohistoria.

Íntimamente ligado al concepto de etnicidad está el de etnogénesis, describible como el proceso de emergencia, formación y mantenimiento de un grupo étnico cuyos rasgos y características culturales lo diferencian de otros grupos vecinos. Tres factores resultan claves a este respecto: la interacción social en un área geográfica determinada que genera el sentido de pertenencia a un colectivo; la conciencia de identidad común, de una misma descendencia real o ficticia; y por último, la existencia de grupos limítrofes que se configuran de la misma manera, frente a los cuales se afirma la identidad. Entre ellos se producen contactos intergrupales, competitividad y conflictos y, por supuesto, cambios en los propios límites o zonas de frontera.

Como puede comprobarse, la etnicidad no es algo estático e inmanente, sino una categoría histórica con raíces en el seno de las propias prácticas sociales de los grupos (Ruiz Zapatero y Álvarez-Sanchís 2002: 255): se trata de un proceso más que de una entidad. Sin embargo, no por ello hay que asumir que las identidades étnicas tienen que reinventarse continuamente. Este último planteamiento, basado en un instrumentalismo mal entendido y en la falta de perspectiva diacrónica de numerosos análisis antropológicos y sociológicos, en ocasiones lleva a negar la posibilidad de que pervivan grupos étnicos durante siglos. Como en otros muchos casos, también aquí es recomendable una visión más equilibrada (Jenkins 1997: 51). Es cierto que algunas etnias son creaciones efímeras determinadas por condicionamientos de tipo económico o político, pero también se conocen grupos étnicos que perviven considerables períodos de tiempo, lo cual no implica su inmovilismo: los Saamis o Mapuches del siglo XVIII no son los mismos que los del siglo XXI, pero eso no excluye una noción de continuidad en la identificación étnica. Se trata, por tanto, de discernir el ritmo y el carácter de las transformaciones, teniendo siempre muy presente que la continuidad de un mismo nombre no significa que su contenido haya permanecido inalterable.
Las definiciones previas conciben la etnicidad como un concepto socialmente construido y dinámico, cuya vinculación con términos como 'raza' o 'sangre' tiene que ser vehementemente rechazado. Además, dada esta condición no puede ser directamente inferida a partir de la genética (Mirza y Dungworth 1995), aun cuando ésta pueda resultar en un futuro de gran utilidad para la identificación de migraciones (Anthony 1990; Prien 2005) o individuos "foráneos" (Pollex et al. 2005), aspectos muy conectados con las interpretaciones étnicas. Por tanto, aunque la paleogenética llegara a ser un elemento más de obtención de 'indicios' (Jones 2006), en nuestra opinión hay que mantener ciertas reservas ante los intentos de conceder 'certificados' de etnicidad pretérita a través del ADN o de los análisis de isótopos de estroncio (Knipper 2004).

Cualquier aproximación arqueológica a la etnicidad requiere una serie de consideraciones teórico-metodológicas previas (Fernández Götz 2009b). La identidad étnica es sólo una más entre las distintas identidades existentes (Díaz-Andreu 1998; Díaz-Andreu et al. 2005), por lo que su estudio no puede desligarse de otros elementos básicos en la construcción social como la jerarquía, el poder, la edad o el género (Jones 1997: 85-86). El concepto de "interseccionalidad" (Davis 2008), centrado en la interacción entre los diversos "ejes identitarios", ayuda a comprender la realidad en toda su complejidad, constituyendo una excelente herramienta teórica para una aproximación holística al estudio de la identidad en general y en sus distintas vertientes. En un mismo grupo étnico es muy probable que los hombres expresen su identidad de forma diferente a las mujeres, o que las clases dirigentes se singularicen empleando marcadores culturales exclusivos (Hodder 1982; Smith 2003). Esto resulta crucial en la búsqueda de posibles 'indicadores arqueológicos': un elemento que puede ser considerado característico de un grupo a su vez es posible que sólo fuera empleado por una parte del mismo en función de criterios de edad, género, estatus, etc.

La etnicidad es también una cuestión de grado: mientras algunos grupos son muy conscientes de su carácter independiente y distinto, y lo acentúan de todas las formas posibles (vestido, adorno personal, decoraciones, etc.), otros tienen menos conciencia de 'pertenencia' y no muestran especial preocupación en su diferenciación (Renfrew 
1990: 177-178). Más aún, la identidad étnica no significa lo mismo para quienes la comparten (Brather 2004: 112-113), pudiendo ser más importante para unos miembros del grupo que para otros (James 1999: 76-77).

Finalmente, la etnicidad opera a más de un nivel (Renfrew 1990: 178). La filiación étnica que ostenta un individuo puede variar en función de las circunstancias, el interlocutor y la situación e interactuar a su vez con tipos de identidad como el género, el estatus o la religión (Díaz-Andreu 1998: 205-206; Díaz-Andreu et al. 2005). De este modo, nunca existe una sola identidad étnica, sino múltiples niveles superpuestos e integrados entre sí, y cuya importancia varía situacionalmente. Distintos tipos de lealtades pueden escalonarse sin que tengan que ser percibidos como contradictorios (Jiménez Díez 2008: 356; Derks y Roymans 2009: 6). Pero esto no quiere decir que las personas elijan libremente qué identidad étnica asumen en cada momento: su elección es situacional, pero dentro de un abanico de distintos niveles que en buena medida son dados (Sommer 2007: 71). Además, esa capacidad individual de elección (Song 2003) difiere entre las modernas sociedades urbanas y multiculturales y las tradicionales donde la identidad es mucho más relacional (Hernando Gonzalo 2002). No afirmamos que en las segundas las personas carezcan de capacidad de elección, sino que suele resultar menor.

La profundidad temporal del fenómeno de la etnicidad es un tema de gran complejidad (Fernández Götz 2008: 121-122), pues la reflexión y práctica de la alteridad/identidad étnica ni es exclusivamente occidental ni de nuestra Modernidad (Ramírez Goicoechea 2007: 131). El término 'etnicidad' y las conceptualizaciones que realizamos de él son una elaboración reciente, un 'constructo' moderno, pero la realidad a la que hacen referencia constituye un hecho bien documentado desde la Antigüedad (Hutchinson y Smith 1996: 3; Jones 1997: 102; Smith 2003: 10-29; Smith 2008) (Fig. 2). Por ello, resulta necesario rechazar aquellas perspectivas que consideran la etnicidad un fenómeno esencialmente contemporáneo, situando su aparición en el contexto del colonialismo europeo, equiparando grupos étnicos con naciones o incluso restringiendo la aplicación del término a sociedades posindustriales.

En estrecha vinculación con la cuestión anterior se encuentra el papel desempeñado por la

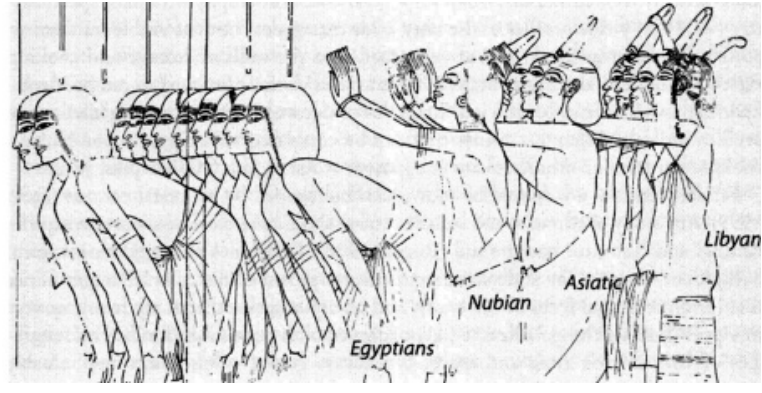

Fig. 2. Estereotipos étnicos de egipcios y pueblos extranjeros: de izquierda a derecha Egipcios, Nubios, Asiáticos y Libios (según Smith 2003).

etnicidad en las sociedades de la Antigüedad: ¿hasta qué punto era un factor relevante a la hora de definir la identidad de personas y comunidades? Con toda seguridad, unidades de referencia como la familia, el oppidum, la aldea, la granja o el valle, así como formas de identidad social como el género, la profesión, la edad o la clase social, debieron constituir elementos mucho más significativos en la vida cotidiana de la mayor parte de las personas que su pertenencia a un determinado grupo étnico. Según Ramírez Goicoechea (2007: 173), la etnicidad, como principio ordenador, puede estructurar sólo algunas parcelas de la vida social o activarse exclusivamente para determinadas situaciones. Sin embargo, esto no es óbice para que, especialmente en momentos de mayor tensión y competitividad entre los grupos, las identidades étnicas adquirieran gran protagonismo (Ruiz Zapatero 2009: 19-21). En última instancia, los grupos étnicos son 'comunidades imaginadas' (Anderson 1983), 'construcciones simbólicas' (Cohen 1985), pero esto no quiere decir que no se perciban como algo real por parte de sus miembros. Los procesos de identificación étnica pueden resultar imaginados, pero no imaginarios (Jenkins 2002: 128).

El primer paso para la construcción de una arqueología de la etnicidad debe ser rechazar la ecuación entre 'cultura arqueológica' y 'grupo étnico' (Shennan 1989; Jones 1997; Sommer 2007; Fernández Götz 2008: 127), superando el lastre que se viene arrastrando desde los tiempos de Kossinna. Para muchos autores la identificación de 'marcadores' individuales no constituye una metodología válida al estar basada en criterios 'subjetivos'. Sin embargo, determinados elementos culturales concretos pueden informar, en 
ocasiones, más sobre identidad étnica que todo un conjunto de tipos arqueológicos. Como han mostrado múltiples estudios antropológicos y etnoarqueológicos (Barth 1969; Hodder 1982; Wiessner 1983), la etnicidad es algo social y culturalmente creado, que convierte en símbolos identitarios conscientes o inconscientes únicamente a determinados aspectos de la cultura, no a todos.

Como a priori prácticamente cualquier elemento de la cultura material puede asumir, o no, una significación étnica, no existen unos marcadores culturales 'objetivos' de etnicidad, aunque sí elementos que, en función de cada contexto específico, teóricamente podrían vincularse con ella. Por tanto, más que de 'criterios' de etnicidad habría que hablar de 'indicios' cuyo valor dependerá del contexto. Desgraciadamente, buena parte de estos posibles indicadores, como la lengua, las leyes y costumbres, las danzas y música, el vestido o los adornos y colores (incluyendo peinados, pinturas corporales, tatuajes, escarificaciones y otros elementos que pueden reflejar tanto identidad individual como de grupo) rara vez dejan huella arqueológica (Fig. 3). Otros, en cambio, son más susceptibles de ser analizados a través de la Arqueología, como por ejemplo la alimentación y la forma de preparar la comida, la variabilidad estilística de las decoraciones cerámicas, los patrones de asentamiento, la deposición de elementos de ajuar con arreglo a pautas normalizadas, el tipo de viviendas, la numismática, la iconografía o las inferencias relativas a la esfera religiosa. La etnicidad a través de la cultura material se puede estudiar a partir de la estructuración de las relaciones entre personas y cosas, y no sólo a partir de las cosas en sí. Es decir, considerando cómo se usa una cerámica, cómo se deposita una lanza en una tumba, cómo se estructura el espacio doméstico, etc. También el análisis arqueológico de las cadenas operativas merece mayor atención futura (Lemonnier 1986). Finalmente contamos con la información que, en contextos concretos, pueden aportar las 'imágenes en negativo'. Así, García Fernández (2007: 131) ha propuesto que entre los Turdetanos la propia ausencia de documentación genera una imagen en negativo que permite diferenciarles de sus veci-

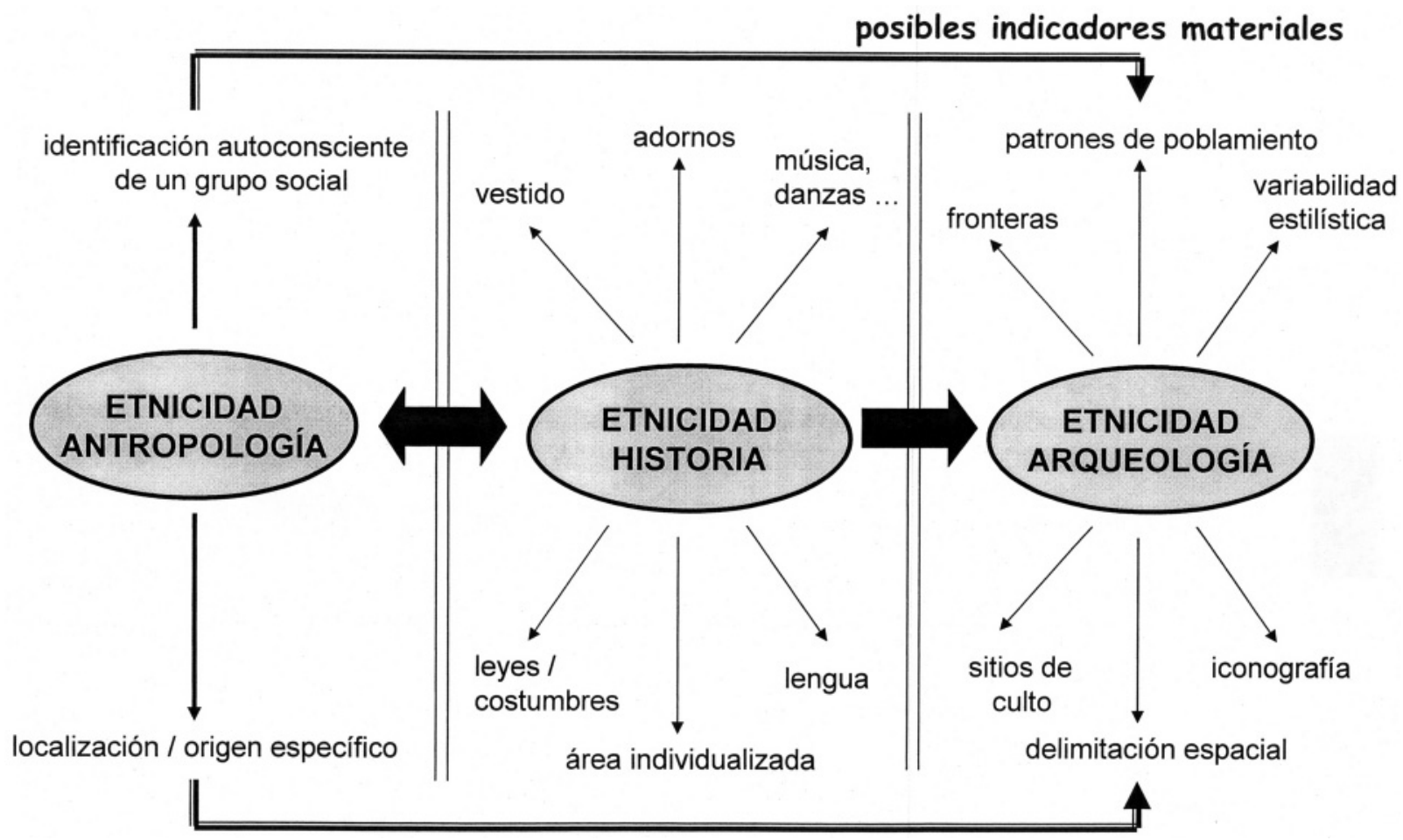

Fig. 3. Características e indicadores de la Etnicidad en Antropología, Historia y Arqueología (según Ruiz Zapatero y Álvarez-Sanchís 2002). 
nos (Púnicos, Bastetanos, etc.) precisamente por lo que no tienen o, mejor dicho, por lo que no expresan o expresan de otra manera. Por otra parte, según Gassowski (2003: 13) uno de los elementos 'tangibles' de la etnicidad goda sería la carencia de armas en los enterramientos.

La falta de aspectos de la cultura material que puedan ser considerados per se criterios 'inequívocos' u 'objetivos' de etnicidad no quiere decir que, dentro de cada contexto cultural específico, la elección sea arbitraria o mecánica. Muy al contrario, la expresión de la etnicidad a través de la cultura material está ligada a las disposiciones estructurales del habitus (Jones 1997: 120), afirmación sustentada por trabajos etnoarqueológicos como los de Hodder (1982) o Larick (1986). Dicho esto, una de las principales dificultades es discernir los elementos materiales con significación étnica de los que expresan formas distintas de identidad cultural. Siguiendo de cerca las tesis de Jones (1997: 125-126), en nuestra opinión la única respuesta pasa por el análisis diacrónico de los contextos culturales a partir de una variedad de fuentes y clases de datos (véanse los ensayos prácticos de Smith 2003; Roymans 2004). Sólo así será posible comprender la expresión de la identidad a través de la cultura material y su uso en la definición de límites étnicos. Se tendrá siempre muy presente que los indicadores étnicos no están fijados de forma permanente, sino sometidos a redefiniciones a lo largo del tiempo, y que un mismo elemento puede marcar diferentes tipos o facetas de la identidad, por lo que interpretaciones alternativas no son necesariamente excluyentes. Valga señalar que ciertos tipos de fíbulas manifiestan a la vez una identidad compartida y una determinada posición social.

En esta labor no resulta determinante si los símbolos materiales fueron utilizados de forma consciente o inconsciente, ya que los elementos culturales seleccionados siempre habrían sido activos en la estructuración o re-estructuración del habitus y de la sociedad (Jones 1997: 118-119). En este contexto resulta apropiada la reflexión de González Ruibal (2003: 137) de que la mayor parte de las cuestiones ideológicas en una sociedad quedan en el terreno de lo no verbalizado. Por tanto, si bien debemos admitir que los grupos étnicos (ethnic communities, Smith 2008) precisan de una identificación autoconsciente, la posible expresión material de su identidad étnica puede ser, en muchos casos, inconsciente.

\section{LA ETNICIDAD DESDE LA PERSPECTIVA DE LA PROTOHISTORIA}

Las aproximaciones a la etnicidad se han venido centrando en la investigación de la Edad del Hierro, algo natural dado que la incipiente disponibilidad de textos y etnónimos ayuda a plantear la búsqueda de identidades étnicas en el registro arqueológico (Fernández Götz 2008: 133-137; Ruiz Zapatero 2009). Adoptando una perspectiva europea, cabe diferenciar dos grandes tradiciones en la investigación protohistórica. En la de la arqueología del ámbito mediterráneo la temprana disponibilidad de fuentes escritas ha desarrollado una rica metodología de interacción entre Arqueología e Historia Antigua (Cornell y Lomas 1997; Hall 1997, 2002; Malkin 2001; Greco 2002; Moscati 2002; Siapkas 2003; Lomas 2004). La segunda es la arqueología de las poblaciones prerromanas de Europa central y septentrional (Wells 1998, 2001; James 1999; Kristiansen 2001; Krausse 2006; Collis 2007). La denominada 'Hispania Céltica' quedaría, de alguna manera, en una posición intermedia.

Una cuestión básica en cualquier acercamiento es la 'escala' de análisis adoptada. La etnicidad puede 'explorarse' a muy diversos niveles, desde regiones geográficas como el Noroeste hispano hasta una agrupación de tumbas en la necrópolis de una polis de la Magna Grecia. Tradicionalmente, la investigación ha centrado su interés en macrocategorías (Grossgruppen) como 'Celtas', 'Germanos' o 'Iberos' (Lund 1998; Collis 2003; Brather 2004). En cambio, permanecen en buena medida inexploradas las posibilidades de analizar los correlatos materiales de agrupaciones más reducidas (tribal ethnicities en Roymans 2004 o ethnic communities en Smith 2008), cuyas características podrían corresponderse mejor con lo que desde una perspectiva antropológica podríamos considerar como grupos étnicos en sentido estricto. Por fortuna, vamos contando ya con algunos estudios modélicos como el de Roymans (2004) y con interesantes aproximaciones en esta dirección en la Península Ibérica (Ruiz Zapatero y Álvarez-Sanchís 2002; García Fernández 2007) (Fig. 4).

Los intentos citados llevan a reflexionar sobre los límites y posibilidades de los testimonios escritos sobre grupos étnicos. El apoyo que supone contar con este tipo de informaciones aumenta la 


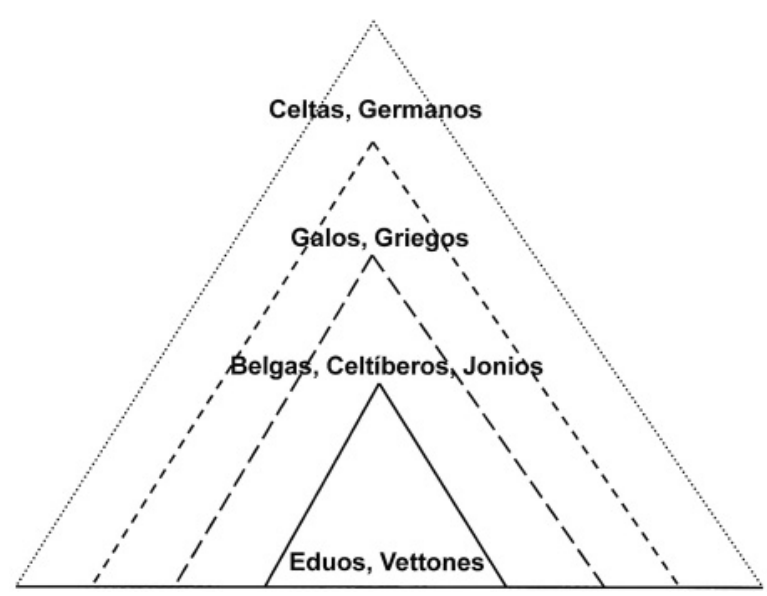

Fig. 4. Niveles tradicionalmente asumidos como étnicos en los estudios de Edad del Hierro (elaboración propia, inédita).

plausibilidad de cualquier propuesta que pretenda relacionar rasgos culturales y etnicidad. De hecho, se acrecienta el consenso respecto a que los estudios arqueológicos sobre la identidad étnica necesitan el concurso de ciertas referencias literarias como punto de partida (Hall 1997, 2002; Boissinot 1998; Roymans 2004; Derks y Roymans 2009; Ruiz Zapatero 2009), fundamentalmente para discernir la etnicidad de formas de identidad de grupo no construidas sobre una base étnica (Mac Sweeney 2009). Es imposible concluir que a una cultura material homogénea corresponda un grado de etnicidad uniforme, ya que la correlación entre rasgos lingüísticos, cultura material y grupo étnico no siempre resulta operativa (Ruby 2006: 59).

Sin embargo, pese a su importancia, las informaciones escritas en ningún caso deben ser aceptadas de forma acrítica, precisándose del análisis minucioso de cada contexto específico. Los problemas se incrementan notablemente cuando se trata de fuentes exoétnicas, es decir, externas al contexto cultural que describen, caso de los testimonios literarios grecolatinos sobre las poblaciones protohistóricas de la Península Ibérica o la Europa Templada. Parece indudable que las descripciones de los autores clásicos, tan pródigas en imágenes estereotipadas del 'bárbaro' como prototipo del 'Otro', no proporcionan una visión 'objetiva' de las sociedades con las que interactuaron. Junto a su carácter incompleto y fragmentario, la interpretatio del extranjero puede ignorar $\mathrm{y} / \mathrm{o}$ falsear las situaciones reales y además las categorías etno-culturales empleadas por los observadores de tiempos pasados no son exactamente las mismas que se manejan actualmente en Antropología y Sociología (Ruiz Zapatero 2009: 18-19). Como reacción, no son pocos los investigadores que cuestionan y aun niegan abiertamente la validez de las fuentes clásicas para el conocimiento de las sociedades protohistóricas, una solución que, a nuestro juicio, pretende buscar una salida fácil a problemas complejos. Y es que, como defiende González García (2007: 104): “desconfiar de las fuentes no implica, como pretenden sus detractores, que haya que rechazarlas, que dejemos de utilizarlas". Frente a las posturas poscoloniales más hipercríticas (cuyos excesos denuncian incluso autores como Woolf 2009), necesitamos una lectura contextual de los textos y una valoración de sus contenidos a partir del análisis de los factores que han actuado sobre su elaboración. En esta tarea hay que valorar múltiples factores, como la época en que fueron escritos, el género literario al que pertenecían, el grado de conocimiento geográfico $\mathrm{y}$ etnográfico existente en cada momento, el contexto histórico de los autores, su formación literario/filosófica, sus prejuicios ideológicos y políticos e incluso sus propios avatares biográficos (García Fernández 2007: 123). Todo ello sin minusvalorar en ningún momento las dificultades para contrastar datos históricos y arqueológicos, ya que es muy posible que ambos proporcionen perspectivas contradictorias, pero aun así complementarias, sobre la identidad en el pasado. En definitiva, y pese a los problemas que plantean, los textos grecolatinos constituyen una fuente de primer orden para el conocimiento de las sociedades de finales de la Edad del Hierro y por ende también de su etnicidad (Champion 1985; Woolf 2009); renunciar a ellos constituiría un error similar a desechar el enorme caudal de informaciones escritas en el marco de la conquista hispana del continente americano.

Si seguimos la propuesta realizada por Smith (2008: 30-31), habremos de convenir en que cuando aparecen etnónimos en las fuentes escritas nos encontramos ante uno de los tres niveles descritos por este autor. Se trata de discernir si estos nombres hacen referencia principalmente a categorizaciones externas aplicadas a poblaciones que carecen del sentido de autoconciencia que se les asigna desde fuera (ethnic categories) o si por 
el contrario los etnónimos reflejan una identidad conscientemente asumida desde una perspectiva emic (ethnic communities). Aun a riesgo de simplificar una realidad mucho más compleja, y haciendo una interpretación de la clasificación aportada por Smith, podríamos decir que las ethnic categories corresponderían a la escala de macrocategorías como 'Celtas' o 'Germanos', ethnic networks a agrupaciones como Belgas o Etruscos y ethnic communities a entidades como Vettones, Eduos o Atenienses.

Cualquier aproximación a las ethnic communities enfrenta el problema de partida de que a menudo su existencia es conocida a través de fuentes exoétnicas (Plácido Suárez 2009; Woolf 2009). Es bien conocido en contextos como el africano que, en principio, los grupos a quienes se aplican estas conceptualizaciones externas no tienen por qué asumirlas (Amselle y M'bokolo 2005). Por tanto, se trata de intentar dilucidar, en la medida de lo posible, si las categorías étnicas recogidas en los textos grecolatinos eran 'constructos' impuestos desde el exterior o correspondían a realidades emic. Entre los testimonios que pueden ofrecer más claves al respecto se encuentran los epigráficos, por desgracia tremendamente exiguos con anterioridad a la conquista romana. No obstante, vamos contando ya con algunas referencias aisladas, entre las que destacamos dos inscripciones. La primera es un grafito con el nombre ELUVEITIE, escrito en caracteres etruscos sobre una cerámica hallada en Mantua (norte de Italia) y datada alrededor del 300 a. C. (Vitali y Kaenel 2000). Este gentilicio deriva claramente del etnónimo 'Helvecio' (Vitali y Kaenel 2000: 115-116), constituye el testimonio contemporáneo más antiguo sobre un grupo étnico galo (Co1lis 2003: 114, 2007: 525) y prueba la existencia de un cierto tipo de identidad helvecia ya en el siglo IV a. C. (Vitali y Kaenel 2000: 121-122). Por otro lado, en el oppidum de Manching apareció, sobre un recipiente cerámico de los siglos II-I a. C., la inscripción BOIOS (Krämer 1982). Se trata de un nombre personal derivado del etnónimo 'Boios', una situación muy similar a la anterior. Pese a su parquedad y carácter excepcional, estos y otros testimonios parecen indicar que al menos parte de los etnónimos transmitidos por las fuentes no eran una simple invención de los autores clásicos, sino que podrían reflejar, en alguna medida, realidades indígenas. Ello no excluye, por supuesto, la existencia de designa- ciones exógenas ajenas a las realidades locales, ni tampoco que las entidades étnicas transmitidas por las fuentes fueran sólo la escala superior de múltiples niveles identitarios superpuestos.

Las definiciones exoétnicas no carecen de interés, dado que la contraposición con el 'Otro' es un elemento fundamental en los procesos formativos de la identidad étnica (Jiménez Díez 2008: 62; Cardete del Olmo 2009: 32), aunque queda mucho por profundizar en los procesos que genera la constante interacción entre auto-identificación y categorización por parte de otros grupos (Jenkins 1997; Ruby 2006: 40-41). La etnicidad sólo se entiende en su doble vertiente emic y etic (Krausse 2006: 133-134), constituyentes complementarios que han de ser integrados para dar cuenta de un fenómeno tan complejo y dinámico (Fernández Götz 2008: 125-126). Partiendo de la base de que las perspectivas emic son el aspecto esencial de la identidad de las ethnic communities (Smith 2008: 33-34) -de ahí la importancia de contar con una etnicidad históricamente percibida y descrita (Derks y Roymans 2009: 7)-, también hay que reconocer que en su construcción y/o redefinición pueden llegar a desempeñar un papel fundamental las aproximaciones externas (Smith 2003; Roymans 2004). De hecho, en ocasiones, definiciones exoétnicas acaban siendo asumidas por los propios grupos descritos (véanse por ejemplo, Beltrán Lloris 2004 y Burillo 2007 para el caso de los Celtíberos). Si bien las construcciones étnicas de los contextos coloniales son con frecuencia creaciones de las potencias colonizadoras (Amselle y M'bokolo 2005) y siempre hay que tener muy en cuenta cómo los Estados en expansión van conformando, etiquetando y sellando la realidad de 'los Otros' (Scott 2009), las construcciones externas también pueden recorrer el camino inverso y acabar siendo aceptadas por las propias comunidades colonizadas como marco identitario (Álvarez Martí-Aguilar 2009: 89). Las definiciones etic constituyen, en definitiva, una parte esencial de la etnicidad: precisamente porque las identidades se construyen en función del 'Otro', las percepciones externas influyen sobre la percepción y definición de la propia identidad. Por último, las perspectivas externas pueden permitir identificar, en ocasiones, elementos culturales constitutivos de una determinada identidad étnica que no han sido conscientemente percibidos o asumidos por los propios actores. 
Un aspecto sobre el que nos gustaría llamar la atención es la frecuente identificación entre procesos étnicos y políticos: no sólo no están en contradicción sino que se complementan perfectamente en los procesos de construcción colectiva, como muestran numerosos ejemplos del Mundo Antiguo (Cruz Andreotti y Mora Serrano 2004; Roymans 2004; Burillo 2007; Derks y Roymans 2009). Las perspectivas instrumentalistas han puesto de relieve el importante papel que puede jugar la etnicidad a la hora de reforzar y preservar la cohesión de formaciones sociopolíticas. Derks y Roymans (2009: 1) llegan a afirmar: It is politics that define ethnicity, not vice versa. Se ha argumentado incluso que la construcción de un grupo étnico precisa de un poder político que dé forma, fomente y sostenga el sentimiento étnico-genealógico y territorial (Cardete del Olmo 2006: 191-192, 2009: 32). Ello, sin tener que ser necesariamente generalizable, parece perfectamente aplicable a numerosas entidades como las poleis griegas o las etnias galas (Eduos, Arvernos...), en las que era habitual la coincidencia entre el grupo étnico y el político.

Nos gustaría terminar estas reflexiones con una propuesta de análisis arqueológico estructurada en tres apartados, que por supuesto constituye sólo una de las múltiples formas posibles de aproximación al estudio de la etnicidad protohistórica (Fernández Götz 2008: 135-137; Ruiz Zapatero 2009: 19-23) (Fig. 5):

1) El análisis parte de un marco espacio-temporal para el cual contamos con referencias escritas sobre grupos étnicos, para establecer a partir de ahí una contrastación crítica entre la distribución de los elementos de la cultura material y los restantes tipos de fuentes disponibles. En definitiva, se buscan posibles correlatos arqueológicos de una etnicidad textualmente definida, teniendo siempre muy presente que las informaciones de las fuentes literarias no dejan de ser aproximativas y que, sobre todo cuando se trata de descripciones exoétnicas, pueden contener importantes distorsiones. Como ya se ha indicado, determinar su grado de plausibilidad precisa del análisis minucioso de cada contexto específico. Resulta indispensable tomar como área de estudio un territorio que sobrepase significativamente la extensión del grupo o grupos a analizar, así como un conocimiento lo más detallado posible de factores como la demografía, el tipo de organización social y las formas de subsistencia, comercio e intercambio entre los grupos. El objetivo es de- terminar la existencia y funcionamiento de 'marcadores' étnicos individuales, rechazando así la tradicional y fallida asociación entre grupo étnico y cultura arqueológica. La identificación de dichos elementos culturales específicos requerirá siempre de una amplia y detallada discusión previa sobre las interpretaciones alternativas y/o complementarias que pueden proponerse para explicar sus pautas de distribución. En esta tarea debemos tener en cuenta tanto los diversos niveles en los que se articula la identidad como los múltiples problemas derivados del uso de fuentes exoétnicas y la posibilidad real de que en ocasiones no se identifique ningún indicador étnico. Además, resaltamos que no se trata sólo de proponer adscripciones étnicas de ciertos elementos de la cultura material, sino sobre todo de lograr una mayor comprensión de los contextos políticos, económicos y religiosos en los cuales se insertan los procesos de construcción y transformación de la etnicidad.

2) En los casos donde haya sido posible determinar algún tipo de 'marcador étnico', el siguiente paso es intentar analizar de forma retrospectiva cómo se comportan los indicadores anteriormente definidos. En teoría, algunos podrán ser seguidos en el tiempo, por lo que habrá que tratar de 'rastrear' su continuidad en el registro arqueológico; otros, en cambio, habrán desaparecido. Al mismo tiempo entrarán en juego nuevos elementos de la cultura material que, analizados a su vez en áreas amplias, podrán sugerir diversos significados, sin descartar que entre ellos se encuentre también el de un hipotético carácter como marcadores de etnicidad. Este análisis se encuentra sujeto a dos importantes limitaciones: la continuidad de un elemento no implica necesariamente la continuidad en su significado y función; y la profundidad temporal de la retrospectiva estará reducida, en el mejor de los casos, a unas pocas centurias.

3) Finalmente, en toda aproximación resultará imprescindible analizar cómo se articula la interrelación entre los diversos tipos de identidad social, así como el papel activo que desempeña la cultura material en la configuración y negociación de la identidad étnica hacia el interior del grupo y en relación con otros grupos limítrofes. La comparación con casos históricos, etnográfi$\cos$ y etnoarqueológicos no ofrecerá respuestas directas, pero puede aportar interesantes claves interpretativas. 


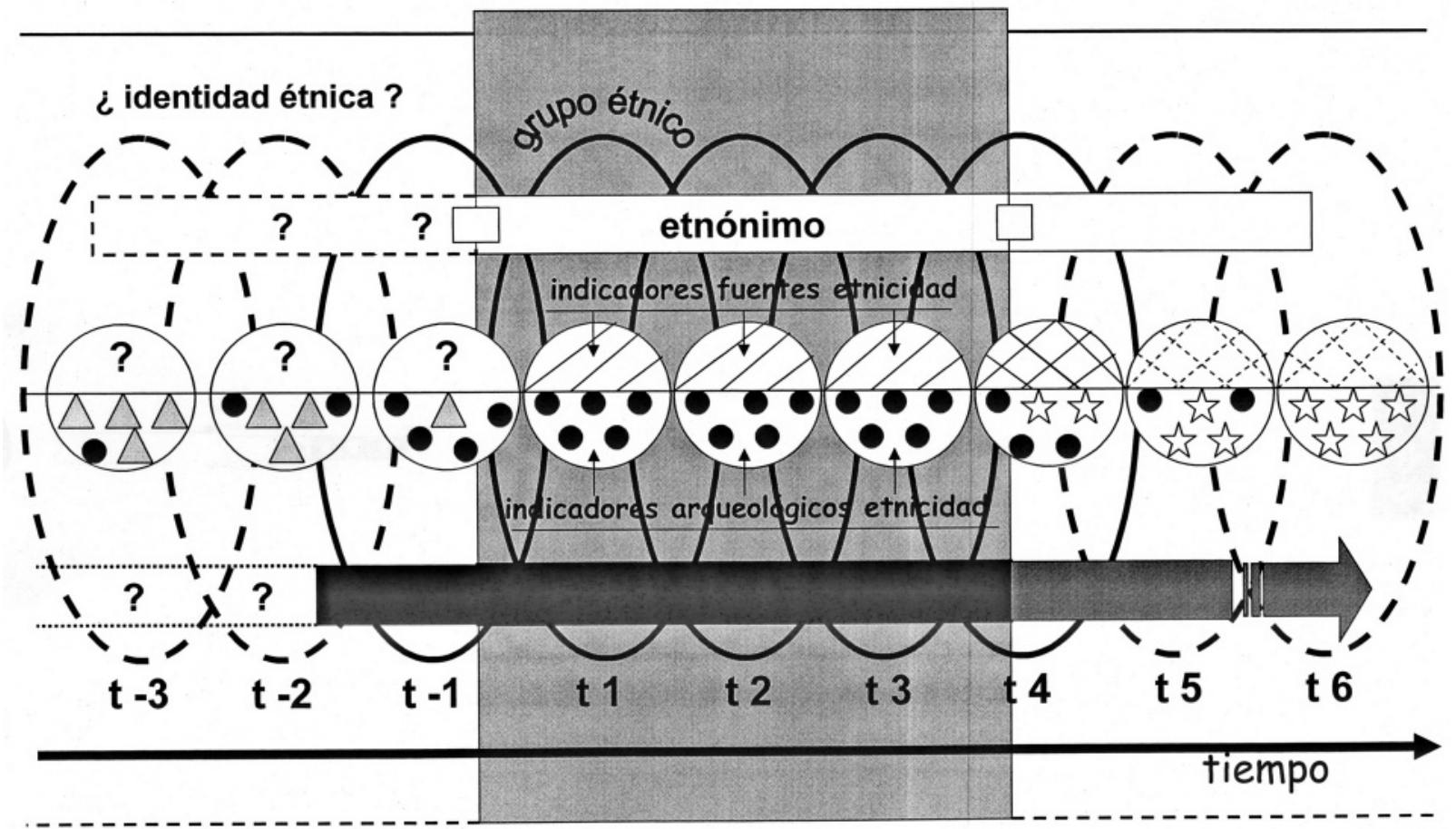

FASE ANTERIOR A CONTACTO

FASE de CONTACTO

FASE de ABSORCIÓN

Fig. 5. La identidad étnica definida en la fase de contacto y las posibilidades anteriores ( $\mathrm{t}-$ ) y posteriores $(\mathrm{t})$, considerando los indicadores de las fuentes escritas y los de la Arqueología. Puntos negros = indicadores de etnicidad de la fase de contacto, de los que alguno tiene origen en la fase anterior y alguno se prolonga en la de absorción; triángulos $=$ otros indicadores propios de la fase anterior; estrellas = indicadores característicos de la fase de absorción (según Ruiz Zapatero 2009).

En definitiva, estamos convencidos de que la exploración de identidades étnicas en la Edad del Hierro, pese a los múltiples problemas y limitaciones que plantea, presenta interesantes posibilidades de futuro. Para su desarrollo consideramos fundamental realizar exhaustivos estudios arqueológicos de casos concretos, profundizar en la hermenéutica de los textos escritos y de modo constante contrastar y discutir los resultados con la conceptualización de la etnicidad en las distintas disciplinas sociales. Además, habrá que tener muy en cuenta la dimensión demográfica de los grupos, el conocimiento de sus matrices socioeconómicas y la cronología de los procesos de etnogénesis a escala de generaciones humanas.

\section{BIBLIOGRAFÍA}

Almagro-Gorbea, M. y Ruiz Zapatero, G. (eds.) 1992: Paleoetnología de la Península Ibérica. Complutum Extra 2-3. Madrid.
Álvarez Martí-Aguilar, M. 2009: "Identidad y etnia en Tartesos". En I. Sastre Prats (coord.): Arqueología Espacial 27: 79-111.

Álvarez-Sanchís, J. R. 1999: Los Vettones. Bibliotheca Archaeologica Hispana 1, Real Academia de la Historia. Madrid.

Amselle, J.-L. y M'bokolo, E. (eds.) 2005: Au cæeur de l'ethnie: Ethnies, tribalisme et État en Afrique. Éditions La Découverte. París.

Anderson, B. 1983: Imagined communities: Reflections on the origins and spread of nationalism. Verso. Londres.

Anthony, D. W. 1990: "Migration in Archeology: The Baby and the Bathwater". American Anthropologist 92 (4): 895-914.

Arnold, B. 1990: "The past as propaganda: totalitarian archaeology in Nazi Germany". Antiquity 64: 464-478.

Arnold, B. 1992: "The past as propaganda: How Hitler's archaeologists distorted European prehistory to justify racist and territorial goals". Archaeology July/August: 30-37. 
Arnold, B. 2006: “Arierdämmerung: race and archaeology in Nazi Germany”. World Archaeology 38 (1): 8-31.

Banks, M. 1996: Ethnicity: Anthropological Constructions. Routledge. Londres, Nueva York.

Barth, F. (ed.) 1969: Ethnic Groups and Boundaries. The Social Organization of Culture Difference. Little Brown. Boston.

Beltrán Lloris, F. 2004: "Nos Celtis genitos et ex Hiberis. Apuntes sobre las identidades colectivas en Celtiberia". En G. Cruz Andreotti y B. Mora Serrano (eds.): Identidades étnicas-Identidades políticas en el mundo prerromano hispano. Servicio de Publicaciones de la Universidad de Málaga. Málaga: 87-145.

Bentley, G. C. 1987: "Ethnicity and Practice". Comparative Studies in Society and History 29 (1): 2455.

Binford, L. R. 1962: "Archaeology as Anthropology". American Antiquity 28: 217-225.

Binford, L. R. 1965: "Archaeological systematics and the study of cultural process". American Antiquity 31: 203-210.

Boissinot, P. 1998: “Que faire de l'identité avec les seules méthodes de l'archéologie?'. En A. D'Anna y D. Binder (eds.): Production et identité culturelle: actualité de la recherche. Rencontres meridionales de Préhistoire récente (Arles, 1996). Editions APDCA. Antibes: 17-26.

Bosch Gimpera, P. 1932: Etnologia de la Península Ibèrica. Alpha. Barcelona.

Bourdieu, P. 1972: Esquisse d'une théorie de la pratique. Droz. Ginebra, París.

Bourdieu, P. 1980: Le sens pratique. Minuit. París.

Brather, S. 2004: Ethnische Interpretationen in der frühgeschichtlichen Archäologie. Geschichte, Grundlagen und Alternativen. RGA Ergänzungsbd. 42, Walter de Gruyter. Berlín, Nueva York.

Brubaker, R. 2004: Ethnicity without Groups. Harvard University Press. Cambridge (Massachusetts), Londres.

Burillo, F. 2007: Los Celtíberos. Etnias y Estados. Crítica. Barcelona.

Cardete del Olmo, M. ${ }^{a}$ C. 2006: "La etnicidad como un arma ideológico-religiosa en la Antigua Grecia: el caso del Monte Liceo". Spal 15: 189-203.

Cardete del Olmo, M. ${ }^{\text {a }}$ C. 2009: "Construcciones Identitarias en el mundo antiguo: arqueología y fuentes literarias. El caso de la Sicilia Griega”. En I. Sastre Prats (coord.): Arqueología Espacial 27: 29-46.

Clarke, D. L. 1968: Analytical Archaeology. Methuen. Londres.

Cohen, A. P. 1985: The Symbolic Construction of Community. Ellis Horwood. Londres, Nueva York.

Collis, J. 2003: The Celts. Origins, Myths and Inventions. Tempus. Stroud.

Collis, J. 2007: "The polities of Gaul, Britain, and Ireland in the Late Iron Age". En C. Haselgrove y
T. Moore (eds.): The Later Iron Age in Britain and Beyond. Oxbow Books. Oxford: 523-528.

Cornell, T. y Lomas, K. (eds.) 1997: Gender and Ethnicity in Ancient Italy. Accordia Specialist Studies on Italy 6 . Londres.

Cruz Andreotti, G. y Mora Serrano, B. (eds.) 2004: Identidades étnicas-Identidades políticas en el mundo prerromano hispano. Servicio de Publicaciones de la Universidad de Málaga. Málaga.

Champion, T. C. 1985: "Written sources and the study of the European Iron Age". En T. C. Champion y J. V. S. Megaw (eds.): Settlement and Society. Aspects of West European Prehistory in the first Millenium B.C. Leicester University Press. Leicester: 922.

Childe, V. G. 1929: The Danube in Prehistory. Clarendon Press. Oxford.

Davis, K. 2008: "Intersectionality as buzzword: a sociology of science perspective on what makes feminist theory successful". Feminist Theory 9 (1): 67-86.

Derks, T. y Roymans, N. 2009: "Introduction". En T. Derks y N. Roymans (eds.): Ethnic Constructs in Antiquity: The Role of Power and Tradition. Amsterdam University Press. Amsterdam: 1-10.

Díaz-Andreu, M. 1998: "Ethnicity and Iberians: the archaeological crossroads between perception and material culture". European Journal of Archaeology 1 (2): 199-218.

Díaz-Andreu, M.; Lucy, S.; Babic, S. y Edwards, D. N. 2005: The Archaeology of Identity. Approaches to gender, age, status, ethnicity and religion. Routledge. Londres, Nueva York.

Díaz-Andreu, M. y Smith, A. D. (eds.) 2001: Nationalism and Archaeology. Blackwell. Londres.

Díaz Santana, B. 2003: "Los celtas. Identidad, etnicidad y arqueología”. Spal 12: 299-316.

Eriksen, T. H. 1993: Ethnicity and Nationalism: Anthropological Perspectives. Pluto Press. Londres.

Fenton, S. 2003: Ethnicity. Polity Press. Cambridge.

Fernández Götz, M. A. 2008: La construcción arqueológica de la etnicidad. Serie Keltia 42. Editorial Toxosoutos. Noia.

Fernández Götz, M. A. 2009a: "Gustaf Kossinna: análisis crítico de una figura paradigmática de la arqueología europea". Arqueoweb. Revista sobre Arqueología en Internet 11 http://www.ucm.es/ info/arqueoweb/numero11/conjunto11.htm consulta 26-VI-2011.

Fernández Götz, M. A. 2009b: "La etnicidad desde una perspectiva arqueológica: propuestas teóricometodológicas". Espacio, Tiempo y Forma, Serie II, Historia Antigua 22: 187-199.

García Fernández, F. J. 2007: “Etnología y etnias de la Turdetania en época prerromana". Cuadernos de Prehistoria y Arqueología Universidad Autónoma de Madrid 33: 117-143. 
Gassowski, J. 2003: “Is Ethnicity Tangible?”. En M. Hardt, Ch. Lübke y D. Schorkowitz (eds.): Inventing the Pasts in North Central Europe. The National Perception of Early Medieval History and Archaeology. Gesellschaften und Staaten im Epochenwandel 9, Peter Lang. Frankfurt am Main: 917.

Gehrke, H.-J. 2000: "Mythos, Geschichte und kollektive Identität. Antike exempla und ihr Nachleben". En D. Dahlmann y W. Potthoff (eds.): Mythen, Symbole und Rituale. Die Geschichtsmächtigkeit der Zeichen in Südosteuropa im 19. und 20. Jahrhundert. Heidelberger Publikationen zur Slavistik 14, Peter Lang. Frankfurt am Main: 1-24.

Giddens, A. 1984: The Constitution of Society: outline of the theory of structuration. Polity Press. Cambridge.

Glazer, N. y Moynihan, D. P. 1975: "Introduction". En N. Glazer y D. P. Moynihan (eds.): Ethnicity: theory and experience. Harvard University Press. Cambridge, Massachusets: 1-26.

González García, F. J. 2007: “Celtismo e historiografía en Galicia: en busca de los celtas perdidos". En F. J. González García (coord.): Los pueblos de la Galicia céltica. Akal. Madrid: 9-130.

González Ruibal, A. 2003: La experiencia del Otro. Una introducción a la etnoarqueología. Akal. Madrid.

González Ruibal, A. 2006-07: Galaicos. Poder y comunidad en el Noroeste de la Península Ibérica. Brigantium 18/19. A Coruña.

González Ruibal, A. (ed.) 2007: “Arqueología Simétrica: Un giro teórico sin revolución paradigmática". Complutum 18: 283-319.

Grau Mira, I. 2005: “Espacios étnicos y políticos en el área oriental de Iberia". Complutum 16: 105-123.

Graves-Brown, P.; Jones, S. y Gamble, C. (eds.) 1996: Cultural Identity and Archaeology. The Construction of European Communities. Routledge. Londres, Nueva York.

Greco, E. (ed.) 2002: Gli Achei e l'identita etnica degli Achei d'Occidente: Atti del Convegno Internazionale di Studi. Fondazione Paestum. Atenas.

Hall, J. M. 1997: Ethnic identity in Greek antiquity. Cambridge University Press. Cambridge.

Hall, J. M. 1998: "Discourse and Praxis: Ethnicity and Culture in Ancient Greece". Cambridge Archaeological Journal 8 (2): 266-269.

Hall, J. M. 2002: Hellenicity. Between ethnicity and culture. The University of Chicago Press. Chicago/Londres.

Herbert, S. 2003: "Excavating Ethnic Strata: The Search for Hellenistic Phoenicians in the Upper Galilee of Israel". En S. Kane (ed.): The Politics of Archaeology and Identity in a Global Context. Archaeological Institute of America. Boston: 101113.
Hernando Gonzalo, A. 2002: Arqueología de la Identidad. Akal. Madrid.

Hobsbawm, E. y Ranger, T. (eds.) 1983: The Invention of Tradition. Cambridge University Press. Cambridge.

Hodder, I. 1982: Symbols in action. Ethnoarchaeological studies of material culture. Cambridge University Press. Cambridge.

Hutchinson, J. y Smith, A. D. 1996: "Introduction". En J. Hutchinson y A. D. Smith (eds.): Ethnicity. Oxford University Press. Oxford, Nueva York: 314.

Insoll, T. (ed.) 2007: The archaeology of identities: a reader. Routledge. Londres, Nueva York.

James, S. 1999: The Atlantic Celts. Ancient People or Modern Invention? British Museum Press. Londres.

Jenkins, R. 1997: Rethinking Ethnicity: Arguments and Explorations. Sage. Londres.

Jenkins, R. 2002: "Imagined but not Imaginary: Ethnicity and Nationalism in the Modern World". En J. MacClancy (ed.): Exotic no More. Anthropology. The University of Chicago Press. Chicago: 114128.

Jenkins, R. 2004: Social Identity. Routledge. Londres, Nueva York.

Jiménez Díez, A. 2008: Imagines Hibridae. Una aproximación postcolonialista al estudio de las necrópolis de la Bética. Anejos de Archivo Español de Arqueología XLIII. Madrid.

Jones, S. 1997: The Archaeology of Ethnicity. Constructing identities in the past and present. Routledge. Londres, Nueva York.

Jones, S. 1998: "Ethnic Identity as Discursive Strategy: the Case of the Ancient Greeks". Cambridge Archaeological Journal 8 (2): 271-273.

Jones, M. 2006: "Archaeology and the Genetic Revolution". En J. L. Bintliff (ed.): A Companion to Archaeology. Blackwell. Oxford: 39-51.

Knipper, C. 2004: "Die Strontiumisotopenanalyse: eine naturwissenschaftliche Methode zur Erfassung von Mobilität in der Ur- und Frühgeschichte". Jahrbuch des Römisch-Germanischen Zentralmuseums Mainz 51: 589-685.

Kossinna, G. 1911: Die Herkunft der Germanen. Zur Methode der Siedlungsarchäologie. Mannus-Bibliothek 6. Würzburg.

Krämer, W. 1982: “Graffiti auf Spätlatènekeramik aus Manching”. Germania 60 (2): 489-499.

Krausse, D. 2006: "The Prehistory of the Celts in South-West Germany. Centralisation processes and Celtic ethnogenesis in the heart of Europe". En D. Vitali (ed.): Celtes et Gaulois, l'Archéologie face à l'Histoire. 2: La Préhistoire des Celtes. Actes de la table ronde de Bologne-Monterenzio, 28-29 mai 2005. Centre archéologique européen, collection Bibracte 12/2. Glux-en-Glenne: 131-142.

Trab. Prehist., 68, N. ${ }^{\circ}$ 2, julio-diciembre 2011, pp. 219-236, ISSN: 0082-5638

doi: $10.3989 /$ tp. 2011.11067 
Kristiansen, K. 2001: Europa antes de la Historia. Península. Barcelona.

Larick, R. 1986: "Age grading and ethnicity in the style of Loikop (Samburu) spears". World Archaeology 18 (2): 269-283.

Legendre, J.-P.; Olivier, L. y Schnitzler, B. (eds.) 2007: L'archéologie nazie en Europe de l'Ouest. Infolio. París.

Lemonnier, P. 1986: "The study of material culture today: toward an anthropology of technical systems". Journal of Anthropological Archaeology 5: 147-186.

Lomas, K. (ed.) 2004: Greek Identity in the western Mediterranean. Papers in honour of Brian Shefton. Brill. Leiden.

Lorrio, A. 2005: Los Celtiberos. Bibliotheca Archaeologica Hispana 25, Real Academia de la Historia. Madrid.

Lund, A. 1998: Die ersten Germanen. Ethnizität und Ethnogenese. C. Winter. Heidelberg.

Mac Sweeney, N. 2009: "Beyond Ethnicity: The Overlooked Diversity of Group Identities". Journal of Mediterranean Archaeology 22 (1): 101-126.

Malkin, I. (ed.) 2001: Ancient Perceptions of Greek Ethnicity. Harvard University Press. Cambridge/ Londres.

Meinander, C. F. 1981: "The concept of culture in European archaeological literature". En G. Daniel (ed.): Towards a history of archaeology. Thames and Hudson. Londres: 100-111.

Miller, D. (ed.) 2005: Materiality. Duke University Press. Durham.

Mirza, M. N. y Dungworth, D. B. 1995: "The potential misuse of genetic analyses and the social construction of 'race' and 'ethnicity"'. Oxford Journal of Archaeology 14 (3): 345-354.

Moerman, M. 1965: "Ethnic Identification in a Complex Civilization: Who are the Lue?". American Anthropologist 67 (5): 1215-1230.

Moscati, L. (ed.) 2002: Identità e prassi storica nel Mediterraneo Greco. Edizioni ET. Milán.

Olsen, B. y Kobylinski, Z. 1991: "Ethnicity in anthropological and archaeological research: a Norwegian-Polish perspective". Archaeologia Polona 29: 5-27.

Plácido Suárez, D. 2009: “Los pueblos prerromanos y sus observadores". En I. Sastre Prats (coord.): Arqueología Espacial 27: 47-61.

Pollex, A.; Sikora, P. y Alt, K. W. 2005: "Zum Nachweis von Fremden im archäologischen Befund". Ethnographisch-Archäologische Zeitschrift 46 (2): 279-294.

Prien, R. 2005: Archäologie und Migration. Vergleichende Studien zur archäologischen Nachweisbarkeit von Wanderungsbewegungen. Habelt. Bonn.
Ramírez Goicoechea, E. 2007: Etnicidad, identidad $y$ migraciones. Ed. Universitaria Ramón Areces. Madrid.

Renfrew, C. 1990: Arqueología y Lenguaje. La cuestión de los orígenes indoeuropeos. Crítica. Barcelona.

Reycraft, R. M. (ed.) 2005: Us and them: Archaeology and Ethnicity in the Andes. Cotsen Institute of Archaeology. UCLA.

Rieckhoff, S. y Sommer, U. (eds.) 2007: Auf der Suche nach Identitäten: Volk - Stamm - Kultur - Ethnos. Internationale Tagung der Universität Leipzig vom 8.-9. Dezember 2000. British Archaeological Reports International Series 1705, Archaeopress. Oxford.

Roymans, N. 2004: Ethnic Identity and Imperial Power: The Batavians in the early Roman Empire. Amsterdam University Press. Amsterdam.

Ruby, P. 2006: "Peuples, fictions? Ethnicité, identité ethnique et sociétés anciennes". Revue des Études Anciennes 108 (1): 25-60.

Ruiz, A. y Molinos, M. 1993: Los Iberos. Análisis arqueológico de un proceso histórico. Crítica. Barcelona.

Ruiz Zapatero, G. 2001: “QQuiénes fueron los celtas? Disipando la niebla: mitología de un collage histórico". En M. Almagro-Gorbea, M. ${ }^{a}$ Mariné y J. R. Álvarez-Sanchís (eds.): Celtas y Vettones. Diputación Provincial de Ávila. Ávila: 72-91.

Ruiz Zapatero, G. (ed.) 2005: "Un círculo de lectores: Miradas sobre los celtas del NO. de la Península Ibérica”. Complutum 16: 151-208.

Ruiz Zapatero, G. 2009: "Etnicidad protohistórica y arqueológica: límites y posibilidades". En I. Sastre Prats (coord.): Arqueología Espacial 27: 13-27.

Ruiz Zapatero, G. y Álvarez-Sanchís, J. R. 2002: "Etnicidad y Arqueología: tras la identidad de los Vettones". Spal 11: 253-275.

Sastre Prats, I. (coord.) 2009: Arqueología Espacial 27.

Scott, J. C. 2009: The Art of Not Being Governed. An Anarchist History of Upland Southeast Asia. Yale University Press. New Haven/Londres.

Shennan, S. J. 1989: "Introduction: archaeological approaches to cultural identity". En S. J. Shennan (ed.): Archaeological Approaches to Cultural Identity. Unwin Hyman. Londres: 1-32.

Siapkas, J. 2003: Heterological ethnicity: Conceptualizing identities in ancient Greece. Acta Universitatis Upsaliensis. Uppsala.

Siegmund, F. 2000: Alemannen und Franken. Archäologische Studie zu Ethnien und ihren Siedlungsräumen in der Merowingerzeit. RGA Ergänzungsbd. 23, Walter de Gruyter. Berlín, Nueva York.

Sklenár, K. 1983: Archaeology in Central Europe: the First 500 Years. Leicester University Press, St. Martin's Press. Nueva York. 
Smith, A. D. 2008: The Cultural Foundations of Nations. Hierarchy, Covenant, and Republic. Blackwell. Oxford.

Smith, S. T. 2003: Wretched Kush: Ethnic identities and boundaries in Egypt's Nubian Empire. Routledge. Londres, Nueva York.

Smolla, G. 1979-80: "Das Kossinna-Syndrom". Fundberichte aus Hessen 19/20: 1-9.

Sommer, U. 2007: "Archäologische Kulturen als imaginäre Gemeinschaften". En S. Rieckhoff y U. Sommer (eds.): Auf der Suche nach Identitäten: Volk - Stamm - Kultur - Ethnos. Internationale Tagung der Universität Leipzig vom 8.-9. Dezember 2000. British Archaeological Reports International Series 1705, Archaeopress. Oxford: 59-78.

Song, M. 2003: Choosing Ethnic Identity. Polity Press. Cambridge.

Veit, U. 1989: "Ethnic concepts in German Prehistory: A case study on the relationships between cultural identity and archaeological objectivity". En S. J. Shennan (ed.): Archaeological Approaches to Cultural Identity. Unwin Hyman. Londres: $35-56$.

Verkuyten, M. 2004: The Social Psychology of Ethnic Identity. Psychology Press. Hove/Nueva York.

Vitali, D. y Kaenel, G. 2000: "Un Helvète chez les Etrusques vers 300 av. J.-C.". Archäologie der Schweiz 23 (3): 115-122.
Vives-Ferrándiz Sánchez, J. 2007: “Colonial encounters and the negotiation of identities in south-east Iberia”. En S. Antoniadou y A. Pace (eds.): Mediterranean Crossroads. Selected Papers of the International Conference, Athens, 10-13th May 2005. Pierides Foundation. Atenas: 537-562.

Voss, B. L. 2008: The Archaeology of Ethnogenesis: Race and Sexuality in Colonial San Francisco. University of California Press. Berkeley.

Weber, M. 1922: Wirtschaft und Gesellschaft. Grundriss der verstehenden Soziologie. Mohr. Tubinga.

Wells, P. S. 1998: "Identity and Material Culture in the Later Prehistory of Central Europe". Journal of Archaeological Research 6 (3): 239-298.

Wells, P. S. 2001: Beyond Celts, Germans and Scythians: Archaeology and Identity in Iron Age Europe. Duckworth. Londres.

Wiessner, P. 1983: "Style and Social Information in Kalahari San Projectile Points". American Antiquity 48 (2): 253-276.

Woolf, G. 2009: "Cruptorix and his kind. Talking ethnicity on the middle ground". En T. Derks y N. Roymans (eds.): Ethnic Constructs in Antiquity: The Role of Power and Tradition. Amsterdam University Press. Amsterdam: 207-217.

Wulff, F. y Álvarez Martí-Aguilar, M. (eds.) 2009: Identidades, culturas y territorios en la Andalucía prerromana. Universidad de Málaga. Málaga. 